\title{
Ecological and Acoustic-call Characteristics of Blyth's Horseshoe bat, Rhinolophus lepidus in Delhi, India
}

\section{Rajlakshmi Mishra', Sumit Dookia ${ }^{1 *}$, Manoj Kumar Singh', Aisha Sultana², Prodyut Bhattacharya ${ }^{\prime}$ \\ ${ }^{1}$ University School of Environment Management, Guru Gobind Singh Indraprastha University (Govt. of NCT of Delhi), Sec. 16 C, Dwarka, New Delhi-110078 \\ ${ }^{2}$ Aravalli Biodiversity Park, Biodiversity Parks Programme, Centre for Environment Management of Degraded Ecosystem University of Delhi, North Campus, New Delhi-1100o7 \\ Study Area: Aravalli Biodiversity Park, Delhi, India \\ Coordinates: $28^{\circ} 33^{\prime} 61^{\prime} \mathrm{N} ; 7^{\circ}{ }^{\circ} 8^{\prime} 59.87^{\prime} \mathrm{E}$}

Key words: Natural cave bats, Morphometrics, Echolocation, Roosting site, Diet assessment.

\section{Introduction:}

The order Chiroptera of the class Mammalia constitutes an interesting group of animals, called bats. This order is the most diverse mammalian order after Rodentia (Srinivasulu \& Srinivasulu, 2001) with more than 1290 species (Fenton \& Simmons, 2014). Till date, a total of 128 species of bats are reported from South Asia, with the microchiropterans being better represented than the megachiropterans (115 vs. 13 species). Among the countries representing South Asia, India has more than $90 \%$ of the total bat diversity of this region, with about 124 species of bats belonging to 8 families are reported from India (Srinivasulu et al., 2010; Saikia et al., 2017).

Rhinolophus lepidus, Blyth 1844 , commonly known as Blyth's Horseshoe bat belongs to the Family Rhinolophidae. Rhinolophidae is a large family of insecteating bats characterized by their muzzle possessing a unique noseleaf resembling a typical horseshoe shape (Bates \& Harrison, 1997).The noseleaf is typically characterized by the presence of the sella and lancets (Fig.1). This species is widespread in South Asia and Southeast Asia. In South Asia the species has been recorded up to an elevation of 2,330 meters above sea level and known from Afghanistan, Bangladesh, Nepal, Bhutan, Pakistan and India (Andhra Pradesh, Assam, Bihar, Delhi, Karnataka, Kerala, Gujarat, Himachal Pradesh, Madhya Pradesh, Maharashtra, Meghalaya, Mizoram, Nagaland, Orissa,

\section{Abstract}

Rhinolophus lepidus, Blyth, 1844, (family Rhinolophidae) is one of the 124 bat species found in India. Till date, 13 species have been reported from Delhi, with one of the identified roosting site present in a natural cave in Aravalli Biodiversity Park. Roost population with direct roost count estimation and morphometric measurements of 65 individuals $\left(490^{\prime \prime}, 16 \%\right)$ were studied at the said location. Roosting behavior, and emergence time for Blyth's horseshoe bat, $R$. lepidus were recorded from June 2015 to September 2016. Echolocation calls were recorded during roosting and release calls during foraging. The recordings revealed a frequency with the maximum energy of $108 \mathrm{kHz}$. This study also reports the phenomenon of torpor in bats from North India in the winter season for the first time.

Rajasthan, Tamil Nadu, Uttarakhand, Uttar Pradesh and West Bengal) (Molur et al., 2002). In Southeast Asia, it has been recorded from Myanmar, Thailand, Cambodia, Vietnam, Peninsular Malaysia and Sumatra. Kingston et al. (2003) have carried out extensive bat surveys and research studies in Southeast Asia.

\section{Methodology:}

Study area: Delhi is the capital of India where there is till now only one known roosting site for Rhinolophus lepidus has been reported, which is a small cave in Aravalli Biodiversity Park (ABP) (Srinivasulu \& Srinivasulu, 2007; Mishra \& Dookia, 2012). The biodiversity park is reclaimed from an old mining site under ecological restoration through Centre for Environment Management of Degraded Ecosystems (CEMDE) and Delhi Development Authority (DDA) under a long-term programme. The site is one of the remnants of Aravalli Hill range, which is the oldest mountain ranges having evolved about 1500 million years ago and extends from Gujarat through Rajasthan to Haryana and Delhi. The spurs of the Aravalli hill range are popularly known as the Delhi Ridge in Delhi which is divided into the Northern, Central, South Central and Southern Ridge as per their directions in the National Capital Territory of Delhi. The Aravalli Biodiversity Park which harbours one of the best habitats with restored old mines are located on the South Central Ridge and spreads over an area of 692 acres. Around 30 biotic communities 
have been developed here after removing the exotic plant, Prosopis juliflora. These communities are represented by various trees species such as Diospyros melanoxylon, Adina cordifolia, Madhuca longifolia, Mitragyna parviflora, Sapindus laurifolius, Aegle marmelos, Prosopis cineraria and Cordia garafinterspersed with grass patches. A small cave inside the park is harbouring a permanent roost of $R$. lepidus, which is located in one of the restored mining ditch converted into a conservatory of ferns and orchids. The cave has a narrow opening and is surrounded by trees like Ficus racemosa, Pterygota alata and Morus alba in the vicinity. Humidity and temperature of this pit are relatively different from all other mines, due to the presence of a functional fernery/orchidarium; where the humidity is being maintained through a periodic sprinkling of water. Hence, this supports an ideal roosting site for R. lepidus.

Data Collection: surveys were conducted in Aravalli Biodiversity Park, Delhi, India, in from June 2015 to September 2016. Fieldwork was interrupted in the winter months of December and January, as Delhi has extreme weather conditions with minimum temperatures falling to as low as $1^{\circ} \mathrm{C}$ on the coldest days. Continuous surveys revealed the presence of roosting site of only one species of bats, R. lepidus. Since the roost was already known and confirmed the presence of Rhinolophus lepidus, Point Count (Kunz, 1988) for the population was done on each visit along with recording the microclimatic parameters (temperature, relative humidity, and light intensity). At this site and in the surrounding areas of the park, 36 hours of night capture sessions through monof ilamentous mistnet of dimensions $12 \mathrm{~m} \mathrm{X} 2.5 \mathrm{~m}$ with mesh-size of $13 \mathrm{~mm}$ were conducted. Scoop netting was done to capture bats from the roost for morphometric analysis.

A standard protocol for ecological observation was as follows:

a)For the population study: to estimate the colony size of the species, the Point Count Method was used (Kunz, 1988). Sex ratio was determined by catching random individuals on each visit with the help of a scoop net and sexing them.

b) Morphometric analysis: external measurements were carried upon on the captured individuals with the help of Mitutoyo digital Vernier caliper with the nearest to $0.01 \mathrm{~mm}$ and the individuals were released immediately. A few voucher specimens were collected for laboratory study of their craniodental measurements and baculum. Measurements were done according to the Bates and Harrison (1997) and Srinivasulu et al. (2010).

c) For signature call record: the echolocation calls were recorded with the $\mathrm{M} 500$ ultrasound microphone by Pettersson with a sampling frequency upto $500 \mathrm{kHz}$. The calls were analyzed using the software BatSound Pro, Version $3.32 @$ Pettersson ElektronikAB.

\section{Results and Discussion:}

Population Study: total Point counts done at multiple times inside the cave showed that the number of individuals ranged between 80 and 150 , giving the average number of individuals present 117. Point Count (Kunz, 1988) was done neglecting the individuals in flight so as to reduce the chances of any repeated count. On all the total 22 surveys conducted during the study period, the colony was found to be male-dominated by the number of males outnumbering the females. Though there are no reports of hibernating bats from this part of the country, bats in winters remain completely inactive in torpor-like conditions.

Torpor in mammals and birds is characterized by a periodic lowering of the set point for body temperature regulation to achieve a hypometabolic state for energy and water conservation. (Wang et al., 1988). Among a wide range of mammals and birds, torpor is often classified as either shallow (daily) torpor or hibernation (seasonal) torpor (Geiser \& Ruf 1995). This bat was found in shallow torpor, which lasted for around 8-10 days in the peak winter season during the December to January month. Among the mammals, members of the order Chiroptera have been widely reported to exhibit torpor (Wang et al., 1988; Barclay et al., 2001; Geiser \& Ruf, 1995; Willis \& Brigham, 2003), though there is no such report from India till date. During the present study, all the individuals of $R$. lepidus were completely inactive in the months of December and January. The activity had started to reduce from late November and continued till mid-February. The individuals remained huddled together in groups inside to keep themselves warm with their eyes shut. When captured, they still remained immobile with the extremely cold body and fur. More physiological studies to assess thermoregulatory mechanisms need to be conducted in-depth on the behavior of bats to ascertain the type of torpor/hibernation exhibited by them in the colder regions of India.

Morphometric measurements: a total of 65 individuals were caught and external morphometric measurements were taken for all of them out of which 48 were males and 17 females. 4 individuals ( 3 males; 1 female) were retained as voucher specimens to carry out cranio-dental measurements and bacular study.

The external measurements from this study are compared to previous literatures (Bates \& Harrison, 1997; 
Srinivasulu et al., 2010) given in Table -1.

Abbreviations used in thestudy:

External measurements: FA: Forearm length; HB: Head Body length; Tail: Tail Length; Ear: Ear Length; Hf: Hindfoot length; Hw: Horseshoe width; Tib: Tibia length; 3mt: Length of the third metacarpal; $4 \mathrm{mt}$ : Length of the fourth metacarpal; 5mt: Length of the fifth metacarpal; 1ph3mt: First phalanx of the third metacarpal; 2ph3mt: Second phalanx of the third metacarpal; 1ph4mt: Length of the first phalanx of the fourth metacarpal; $\mathbf{2 p h} \mathbf{4 m t}$ : Length of the second phalanx of the fourth metacarpal. Cranio-dental measurements: GTL: Greatest length of skull; CBL: Condylobasal length; CCL: Condylocanine length; ZB: Zygomatic breadth; BB: Breadth of braincase; CM3: Maxillary toothrow length; $\mathbf{C M}_{3}$ : Mandibular toothrow length; M1-M1: Posterior palatal width; $\mathbf{C}_{\mathbf{1}}-\mathbf{C}_{1}$ : Anterior palatal width; M: Mandibular length.

All the morphometric measurements were found to be similar with the range given by Bates \& Harrison (1997) and Srinivasulu et al. (2010) except for the ear length which at $13.24 \mathrm{~mm}$ did not fall in the range of $14.5-20.6 \mathrm{~mm}$.

Table 1: External and cranio-dental measurements ( $\mathrm{mm}$ ) of R.lepidus from Aravalli Biodiversity Park, Delhi, India

\begin{tabular}{|c|c|c|c|}
\hline $\begin{array}{l}\text { External } \\
\text { Measurements }\end{array}$ & $\begin{array}{l}\text { Present Study } \\
(\mathrm{n}=65)^{\mathrm{a}}\end{array}$ & $\begin{array}{l}\text { Bates \& Harrison } \\
(1997)^{\text {b }}\end{array}$ & 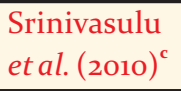 \\
\hline FA & 39.48 & 39.8 & $37 \cdot 0-41.8$ \\
\hline HB & 40.10 & 42.9 & $35.0-54.0$ \\
\hline Tail & 20.4 & 20.4 & $14.0-28.0$ \\
\hline Ear & 13.24 & 16.9 & $14 \cdot 5-20.6$ \\
\hline $\mathrm{HF}$ & $7 \cdot 36$ & 7.6 & $5 \cdot 5-10.0$ \\
\hline TIB & 16.25 & 16.7 & - \\
\hline $3 \mathrm{mt}$ & 31.82 & 30.4 & - \\
\hline $4 \mathrm{mt}$ & 32.96 & 31.4 & - \\
\hline $5 \mathrm{mt}$ & 31.42 & 31.1 & - \\
\hline $1 \mathrm{ph} 3 \mathrm{mt}$ & 12.22 & 11.8 & - \\
\hline $2 \mathrm{ph} 3 \mathrm{mt}$ & 18.03 & $17 \cdot 3$ & - \\
\hline $1 \mathrm{ph} 4 \mathrm{mt}$ & 9.59 & 8.7 & - \\
\hline $2 \mathrm{ph} 4 \mathrm{mt}$ & 11.16 & 10.8 & - \\
\hline \multicolumn{4}{|c|}{ Cranio-dental measurements $(\mathrm{n}=4)(\Sigma / \mathrm{n})$} \\
\hline GTL & $17 \cdot 48$ & 17.2 & - \\
\hline CCL & 14.27 & 14.6 & $13 \cdot 3-15 \cdot 5$ \\
\hline $\mathrm{ZB}$ & 8.05 & 8.2 & $7 \cdot 6-8.8$ \\
\hline $\mathrm{BB}$ & 7.62 & 7.1 & - \\
\hline $\mathrm{C}-\mathrm{M}^{3}$ & 6.51 & 6.1 & $5 \cdot 6-6.8$ \\
\hline$C^{1}-C^{1}$ & 4.11 & 4.0 & - \\
\hline $\mathrm{M}_{3}-\mathrm{M}_{3}$ & 6.2 & $5 \cdot 9$ & - \\
\hline M & 11.13 & 11.0 & $10.0-12.1$ \\
\hline $\mathrm{C}-\mathrm{M}_{3}$ & 6.85 & 6.6 & $6.0-7 \cdot 4$ \\
\hline
\end{tabular}

Length of the baculum :3.61

${ }^{\mathrm{a}}(\Sigma / \mathrm{n}) ;^{\mathrm{b}}$ (mean), ${ }^{\mathrm{c}}$ (range)

Bacular study: the presence of a bone, the baculum, in the penis of most species of bats has long been known but its origin and function are not yet well understood (Sinha, 1976). Thomas (1915) first used the baculum as a taxonomic character.

The baculum was extracted following the standard protocol from Bates et al. (2005). The baculum of $R$. lepidus has an elongated ' $\mathrm{S}$ ' shape with a dorsal bend near the basal cone and a ventral turn near the tip. The dorsal edge of the basal cone has a proximally bulging dorsal knob, which continues on the dorsal surface of the shaft (Fig.-2a). The shaft is cylindrical and tapering towards the tip. The tip is broadly rounded off and generally wide from the dorsal view, and with a longish dorsal bulge, visible well from the lateral aspect (Fig.-2b). The length of the baculum was found to be $3.61 \mathrm{~mm}$. Topal (1975), while describing the bacula of some leaf-nosed bats gave the range of $3.28-3.77 \mathrm{~mm}$ for the baculum of R.lepidus.

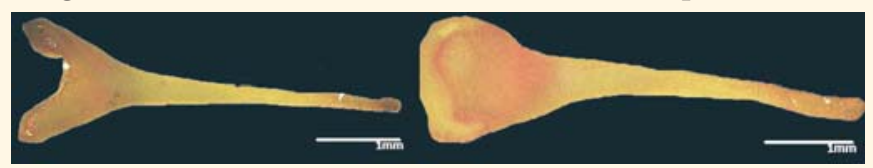

Figure-2: Baculum of R.lepidus. a) Dorsal view; b) Lateral view

Echolocation call characteristics: bat call shapes usually comprise two main components. A constant frequency or CF component, where the frequency remains the same over time, is represented on the spectrogram by the flat horizontal lines (Kunz, 1988). This component may also be a quasi-constant frequency or QCF component where there is a slight variation in frequencies over time resulting in a call shape on the spectrogram with a shallow slope (a typical of a Pipistrelle call) (Scnitzler \& Kalko,1998). A frequency modulated or FM component is where the call sweeps through a range of frequencies over time, represented by the almost vertical lines. Many calls are actually a combination of the two with a FM section and a CF or QCF (Jones, 1999).

Rhinolophus lepidus emitted typical FM/CF/FM calls (Fig. -3). The FM sweeps are often visible at the start and end of the call. The bats were caught in the roost and recorded in ambient noise. The recordings of Rhinolophus lepidus revealed a frequency with maximum energy of $108 \mathrm{kHz}$ (Fig.-4; Table-2). Raghuram et al. (2014) report the F Max of a R. lepidus call at $94 \mathrm{kHz}$ and Wordley et al. (2014) at $102 \mathrm{kHz}$. It is well known that Rhinolophid bat species produce species-specific calls; so this difference can be well attributed to the geographical gradient as the earlier studies have been carried out in the Western Ghats, India.

Table- 2: Temporal and Spectral features of echolocation call of
R. lepidus $\left(n=9^{*}\right)$

( ${ }^{*}$ The values reported are an average of 9 clear calls with the highest signal to noise ratio from each recording) 


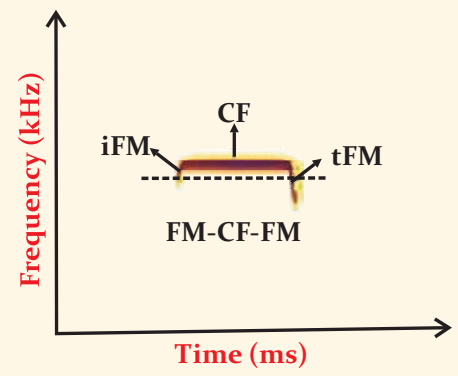

Fig.4. A typical Rhinolophus call FM/CF/FM (FM- Frequency Modulation, CF- Constant Frequency, iFM-Initial Frequency Modulation, tFM-Terminal Frequency Modulation.

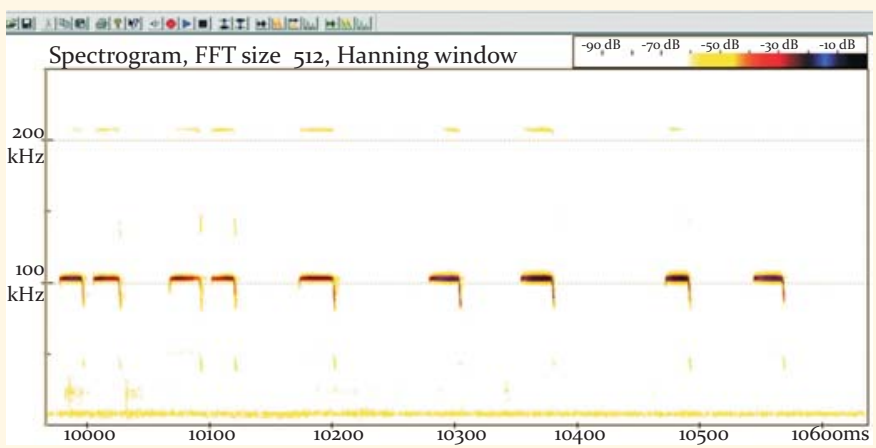

Figure-4: Spectrogram/Oscillogram of R.lepidus call.

Microclimatic conditions and the correlation with emergence time: subterranean ecosystems are characterized by perpetual darkness, constant temperature and high humidity with limited air currents (Biswas \& Shrotriya, 2010). As reported earlier, in the course of study, it was found that emergence from the roost was correlated with the sunset but, delayed by extended twilight during the peak summer season (Biswas \& Kanoje, 1991). The dusk emergence counts show two peaks, the first in late May and early June, and the second from mid to late August. Light intensity was important in triggering the departure of bats from the roost and it was observed that cloud cover delayed the departure time during the rainy season. While it was completely dark inside the cave in early morning and during dusk, in the mid-morning and afternoon, the light intensity inside the cave was found to be around 3-4 lux.

The main entrance of the cave comprises of a narrow hollow passage that opens into a big chamber with no other opening. The roosting site only has a single exit shaded by trees and exploratory flights were generally more extended there. Biswas et al. (2011) found that members of Rhinolophidae occupied the cave-ceiling areas near the twilight-intermediate zone in the caves of Kanger Valley National Park, Chhatisgarh, India. In the present study, since the cave had a single opening, so the twilight zone was very narrow and the bats avoided it for roosting. Heavy rain inhibited emergence and the bats did not emerge from the roost for foraging during rainy days. There was almost every time intermittent activity throughout the night, with many individuals returning and departing, and no indication of seasonal or overnight peaks. Selvanayagam \& Marimuthu (1984) found that male bats in Hipposideros speoris utilized their urine as olfactory cues which enable them to attain an already established order of roosting accurately within the cave; though the same is not proven for R. lepidus in present study. Some bats often returned to the roost in the late night before dawn. The temperature and relative humidity of the cave was regularly recorded. It was found that the inside of the cave was cooler and humid than the outside. Throughout the study period, there was a difference of $3-4^{\circ} \mathrm{C}$ in outer and inner temperatures. Relative humidity inside the cave was recorded at a maximum of $87 \%$ in Late July and minimum at $31 \%$ in early April.

Conservation and future directions: Rhinolophids are known to roost selectively where both macro and microhabitat play an important role in their roost selection (Ponmalar \& Vanitharani, 2014). Rhinolophids usually roost in very visible situations making them even more vulnerable to disturbance (Hutson et al., 2001).The presence of a permanent roost in this cave is a clear indication that the habitats and surroundings are ideal for the roosting of $R$. lepidus. The cave is incidentally also located inside a protected area which further enhances the chances of protection of roost as well as conservation of the species. Outreach can be a powerful tool in helping to minimize anthropogenic threats to species thriving in the wild. In India, bats have several myths associated with their presence. Inside a protected area, it would be advisable to inform visitors about the presence of a permanent roost and also make them aware of the ecosystem services provided by bats, so that people connect to nature and all species coexisting with them.

\section{Acknowledgements:}

The authors are thankful to the Chief Conservator of Forests and Chief Wildlife Warden, Govt. of N.C.T. of Delhi, for providing essential permits to conduct this study. Special thanks are due to Dr. M. Shah Hussain, Scientist-in-Charge, Aravalli Biodiversity Park managed under Centre for Environment Management of Degraded Ecosystem (CEMDE),Uni.of Delhi. RM, SD, MKS and PB are thankful to Dean, University School of Environment Management, Guru Gobind Singh Indraprastha University for providing necessary facilities to conduct this study. RM is thankful to Guru Gobind Singh Indraprastha University for funding this study by the Indraprastha Research Fellowship (IPRF) vide letter no. 1427/2013. MKS is thankful to the Course Coordinator, M.Sc. (Biodiver. Conserv.), University School of Environ. Manag., Guru Gobind Singh Indraprastha University. .

\section{References:}

Barclay R.M.R., Lausen C.L. \& Hollis L. (2001): What's hot and what's not: defining torpor in free ranging birds and mammals. Can. J. Zool., 79:1885-189o.

Bates P., Thong,V.D. \& Bumrungsri, S. (2005): Voucher specimen preparation: Bats. Pub. by: Harrison Institute, Bowerwood 


\section{RESEARCH ARTICLE}

House, St Botolph's Road, Sevenoaks, Kent, TN13 3AQ, England.

Bates P.J.J. \& Harrison D.L. (1997): Bats of the Indian Subcontinent. Pub. by: Harrison Zoological Museum Publications. 258 pp.

Biswas, J. \& Kanoje, R.S. (1991): Seasonal and photoperiodic control of the activity and daily exodus of a colony of cave dwelling bat. JRavishankar University, 4:33-41

Biswas, J. \& Shrotriya, S. (2010): Dandak: a mammalian dominated cave ecosystem of India. Subterran. Biol., 8: 1-7.

Biswas, J., Shrotriya, S., Rajput, Y. \& Sasmal, S. (2011): Impacts of Ecotourism on Bat Habitats in Caves of Kanger Valley National Park, India. Res. J. Environ. Sci., 5(9):752-762.

Fenton, M.B. \& Simmons, N.B. (2014): Bats: a world of science and mystery. Pub. by: University of Chicago Press, Chicago. 303pp.

Geiser, F. \& Ruf, T. (1995): Hibernation versus daily torpor in mammals and birds : physiological variables and classif ication of torpor patterns. Physiol. Zool., 68:935-966.

Hutson, A.M., Mickleburgh, S.P. \& Racey, P.A. (2001): Microchiropteran bats: Global Status Survey and Conservation Action Plan. Pub. by: IUCN/SSC Chiroptera Specialist Group, Switzerland and Cambridge, U.K. 258 pp.

Jones, G. (1999): Scaling of echolocation call parameters in bats. L. Exp. Biol., 202:3359-3367.

Kingston, T., Francis, C.M., Zubaid, A. \& Kunz, T.H. (2003): Species richness in an insectivorous bat assemblage from Malaysia. J. Trop. Ecol.,19:67-79.

Kunz. T.H. \& Kurta, A. (1988): Capture methods and holding devices. 129pp. in Ecological and behavioral methods for the study of bats. Pub. by: Smithsonian Institution Press. Washington D.C. 533. pp.

Mishra, R. \& Dookia, S. (2015): Bats of Delhi. Small Mammals Mail Bi-Ann. Newsl. CCINSA E RISCINSA. 7(1):15-17.

Molur, S., Marimuthu, G., Srinivasulu, C., Mistry, S., Hutson, A.M., Bates, P.J.J., Walker, S., Padmapriya, K. \& Binupriya, A.R. (2002): Status of South Asian Chiroptera: Conservation Assessment and Management Plan (C.A.M.P). workshop report, 2002. Zoo Outreach Organisation, CBSG South Asia and WILD, Coimbatore, India, CD-Rom.

Ponmalar, S. \& Vanitharani, J. (2014): Insect pest management by the horse shoe bats (Rhinolophus species) in the forest ecosystem of Kalakad Mundanthurai Tiger Reserve, India. Scrut. Internal Res. J. Biol. Environ. Sci., 1:5.1-19.
Ambient Science, 2018: Vol. 05(1); 33-37 DOI:10.21276/ambi.2018.05.1.ra02

Raghuram, H., Jain, M. \& Balakrishnan, R. (2014): Species and acoustic diversity of bats in a palaeotropical wet evergreen forest in southern India. Current Sci., 107(4):631-641.

Saikia, U., Csorba, G. \& Ruedi, M. (2017): First record of Hypsogo joffrei (Thomas, 1915) and the revision of Philetor brachypterus (Temminck, 1840) specimens (Chiroptera : Vespertilionidae) from the Indian Subcontinent. Rev. Suisse Zool., 124(1):83-89.

Schnitzler, H.U. \& Kalko, E.K.V. (1998): How echolocating bats search and find food. In T.H. Kunz and P. A. Racey (eds.): Bat Biology and Conservation. Pub. by: Washington: SmithsonianInstitution Press, pp. 183196.

Selvanayagam, P.F.L. \& Marimuthu, G.(1984): Spatial organization of roosting in the insectivorous tropical bat Hipposideros speoris. Behav. Process., 9:113-121.

Sinha, Y.P. (1976): Bacula of Rajasthan Bats. Mammalia, 40(1): 97103.

Srinivasulu, C. \& Srinivasulu, B. (2001): Bats of the Indian subcontinent. Current Sci., 8o(11):1378-138o.

Srinivasulu, C. \& Srinivasulu, B. (2007). Bats of Delhi: An update. BATNET-CCINSANewslett., 8(1-2):30-31.

Srinivasulu, C., Racey, P.A. \& Mistry, S. (2010): A key to the bats (Mammalia: Chiroptera) of South Asia. J. Threat. Taxa 2(7): 1001-1076.

Thomas, O. (1915): The penis bone as a guide to classification of certain squirrels. Ann. Mag. Nat. Hist., 8(15):383-387.

Topal, G. (1975): Bacula of some old world Leaf-nosed bats (Rhinolophidae and Hipposideridae, Chiroptera : Mammalia). Vertebr. Hung., 16:22-53

Wang, L. \& Wolowyk, M. (1988): Torpor in mammals and birds. Can. J. Zool., 66:133-137.

Willis, C.K.R. \& Brigham, R.M. (2003): Defining torpor in freeranging bats: experimental evaluation of external temperature-sensitive radiotransmitters and the concept of active temperature. J. Comp. Physiol., B 173:379-389.

Wordley, C.F.R., Foui, E.K., Mudappa, D., Sankaran, M. \& Altringham, J.D. (2014): Acoustic identification of bats in southern Western Ghats, India. Acta Chiropterol., 16(1): 213222.

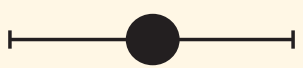

